\title{
Circulating cell-free DNA in serum as a biomarker for diagnosis and prognostic prediction of colorectal cancer
}

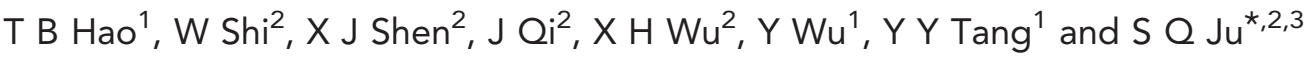 \\ ${ }^{1}$ Medical School of Nantong University, Nantong 226000, Jiangsu Province, China; ${ }^{2}$ Surgical Comprehensive Laboratory, Affiliated \\ Hospital of Nantong University, Nantong 226000, Jiangsu Province, China and ${ }^{3}$ Center of Laboratory Medicine, Affiliated Hospital \\ of Nantong University, 20 Xisi Street, Nantong 226000, Jiangsu Province, China
}

Background: To verify whether the concentrations and integrity index of circulating cell-free DNA (ccf-DNA) in serum may be clinically useful for the diagnosis and progression monitoring of colorectal cancer (CRC) patients.

Methods: Serum samples were collected from 104 with primary CRC, 85 with operated CRC, 16 with recurrent/metastatic CRC, 63 patients with intestinal polyps and 110 normal controls. Long (247 bp) and short (115 bp) DNA fragments in serum were detected by real-time quantitative PCR by amplifying the ALU repeats (ALU-qPCR). Serum carcinoembryonic antigen (CEA) level was detected by ARCHITECT assay.

Results: The median absolute serum ALU115 and ALU247/115 in primary CRC group was significantly higher than those in intestinal polyp and normal control groups (both $P<0.0001$ ), in recurrent/metastatic CRC was significantly higher compared with primary CRC $(P=0.0021, P=0.0018)$ or operated CRC $(P<0.0001$, respectively) and during follow-up, ALU115 and ALU247/115 were increased before surgery and decreased significantly after surgery.

Conclusions: Combined detection of ALU115, ALU247/115 and CEA could improve the diagnostic efficiency for CRC. Serum DNA concentrations and integrity index may be valuable in early complementary diagnosis and monitoring of progression and prognosis of CRC.

Colorectal cancer (CRC) is the third most common newly diagnosed cancer and the third most common cause of cancer death among US men and women. It is also a worldwide problem, with an annual incidence of one million cases and an annual mortality of more than 500000 cases (Ferlay et al, 2010; Jemal et al, 2011). The overall survival of CRC tends to be poor, mainly because most CRC cases are in late stages at the time of diagnosis, and thus losing the opportunity for access to timely and standard treatment. Approximately 50\% of CRC patients ultimately died from distant metastasis (Mutch, 2007). Therefore, the key to CRC treatment is early detection and diagnosis.

Multiple serum markers including carcinoembryonic antigen (CEA) and carbohydrate antigen 19-9 (CA19-9) have been well recognised as tumour markers for CRC. However, not all CRC cases can be diagnosed by CEA or CA19-9 alone owing to unstable detection and incremental concentrations in benign diseases (Ludwig and Weinstein, 2005), and CEA only has a sensitivity of $43 \%$ (Keesee et al, 1996). Therefore, there is an urgent need to find a noninvasive biomarker that can be commonly applied for screening diagnosis, 'early' adjuvant detection of recurrence and monitoring of metastatic CRC (MCRC).

Circulating cell-free DNA (ccf-DNA) in serum or plasma is a promising candidate biomarker for detection, monitoring and prognostic prediction of malignant tumours (Taback and Hoon 2004a, b; Fujimoto et al, 2004; Chan et al, 2008). A study by Leon et al (1977) suggested that the ccf-DNA concentration was significantly increased in cancer patients compared with that in healthy individuals, which was also confirmed by other studies (Sozzi et al, 2003; Banki et al, 2007; Zhong et al, 2007; Zachariah et al, 2008; Ellinger et al, 2009; Hohaus et al, 2009; Paci et al, 2009; 
Hauser et al, 2010; Czeiger et al, 2011; Chen et al, 2013; Qi et al, 2013). Some recent studies have demonstrated that DNA integrity index measured as the ratio of long to short DNA fragments is higher in patients with gynaecologic and breast tumours (Wang et al, 2003; Umetani et al, 2006a; Holdenrieder et al, 2008), gastrointestinal and hepatocellular tumour (Umetani et al, 2006b; Holdenrieder et al, 2008; Mead et al, 2011; Chen et al, 2012; da Silva Filho et al, 2013), urologic tumour (Hanley et al, 2006; Holdenrieder et al, 2008; Gang et al, 2010; Feng et al, 2013), head and neck tumour (Jiang et al, 2006), nasopharyngeal tumour (Chan et al, 2008), melanoma (Pinzani et al, 2011), acute leukaemia (Gao et al, 2010) and malignant pleural effusion (Sriram et al, 2012) than that in healthy controls. These studies are based on the hypothesis that ccf-DNA released from apoptotic cells is uniformly truncated into 185- to 200-bp fragments (Giacona et al, 1998; Umetani et al, 2006b). However, ccf-DNA released from necrotic tumour cells varies in length, which may lead to elevation of DNA with long fragments in serum or plasma (Jahr et al, 2001; Umetani et al, 2006a). Hence, as a minimally invasive biomarker for malignancies, ccf-DNA and its integrity in blood has the high potential for cancer detection and prognosis.

In this study, we measured ccf-DNA fragments by real-time quantitative polymerase chain reaction of ALU repeats (ALUqPCR) on 378 serum samples. Our aim was (1) to extract ccf-DNA by a new accurate and reproducible technique and evaluate this new technique in measuring serum ccf-DNA; (2) compare total levels of ccf-DNA and DNA integrity between normal controls, patients with intestinal polyps and CRC patients to see whether serum ccf-DNA could help diagnose, monitor disease progression and predict prognosis of CRC; and (3) explore the feasibility of combination detection of ccf-DNA and CEA for the diagnosis of $\mathrm{CRC}$ and see whether there is any significant correlation between total level of ccf-DNA, DNA integrity and clinical parameters.

\section{MATERIALS AND METHODS}

Subjects and sample collection. Serum samples from 205 CRC patients, 63 patients with intestinal polyps and 110 normal controls were collected. The CRC group consisted of 104 primary CRC patients, 85 operated patients and 16 patients with recurrent CRC/ MCRC. Continuously, serum samples were collected in 20 of the 104 primary CRC patients who received surgery and were followed up for 1-120 days. The blood samples were obtained from the Departments of General Surgery and Gastroenterology at the Affiliated Hospital of Nantong University between August 2012 and November 2013. The diagnosis of all 205 CRC patients was histologically confirmed. The 110 normal controls were selected from volunteer blood donors of Nantong Blood Center who had no history of autoimmune disease or tissue injury or trauma at the time of examination. Informed consent was obtained from all volunteers before the blood was drawn.

All samples were anonymous with written informed consent. The study was approved by the Human Research Ethics Committee of the Affiliated Hospital of Nantong University. Sera were separated by centrifuging the blood samples at $1600 \mathrm{~g}$ for $10 \mathrm{~min}$ and stored at $-80^{\circ} \mathrm{C}$ for DNA extraction and ARCHITECT assay.

Serum DNA extraction. Serum DNA was extracted using a fast high-throughput automated extraction method that can produce high yields of DNA from serum samples. Based on the principle of magnetic bead adsorption, magnetic beads were released through special magnet adsorption to accomplish the shift between magnetic beads and nucleic acids. After automatic extraction and purification of nucleic acid, DNA from $200 \mu$ l equivalent volume of serum was extracted using Magnetic Bead DNA Extraction Kit
(Tianlong, Xi'an, China) by Nucleic Acid Extraction System (Tianlong NP968, Xi'an, China) following the manufacturer's instructions. DNA was then stored at $-80{ }^{\circ} \mathrm{C}$ until further analysis.

Real-time ALU-PCR. To assess the concentration and integrity index of serum ccf-DNA, both short fragment (115bp) and long fragment $(247 \mathrm{bp})$ from a consensus sequence with abundant genomic ALU repeats were amplified and quantified as described previously (Umetani et al, 2006a,b). The ALU115-bp primer amplified both short (apoptotic) and long (non-apoptotic) DNA fragments, whereas the ALU247-bp primer amplified long nonapoptotic DNA fragments only. The ALU-qPCR result obtained with ALU115 primers represents the total amount of serum DNA. DNA integrity index was calculated as the ratio of ALU-qPCR result (ALU247 and ALU115). The sequences of the primers were as follows: ALU115 - forward, 5' ${ }^{\prime}$-CCTGAGGTCAGGAG TTCGAG- $3^{\prime}$ and reverse, $5^{\prime}$-CCCGAGTAGCTGGGATTACA- ${ }^{\prime}$; ALU247 - forward, 5'-GTGGCTCACGCCTGTAATC-3' and reverse, 5'-CAGGCTGGAGTGCAGTGG-3'.

The reaction mixture for each ALU-qPCR contained $5 \mu$ DNA template, $0.5 \mu \mathrm{l}$ of the each forward and reverse primer (ALU115 or ALU247), $10 \mu \mathrm{l}$ SYBR Green Master Mix (Rox, Weitefeld, Germany) and $4 \mu \mathrm{l}$ double-distilled water in a total reaction volume of $20 \mu \mathrm{l}$ with $95^{\circ} \mathrm{C}$ for $10 \mathrm{~min}$, followed by 35 cycles of $95^{\circ} \mathrm{C}$ for $15 \mathrm{~s}$, and annealing at $64^{\circ} \mathrm{C}$ for $1 \mathrm{~min}$ in 7500 Real-Time PCR System (ABI, Abilene, TX, USA). ALU-qPCR reaction conditions were optimised to yield optimal results to suit the equipment, reagents and conditions of our laboratory. The absolute equivalent amount of serum DNA fragments in each sample was determined using a standard curve with serial dilutions (from 0.222 to $22200 \mathrm{ng} \mathrm{ml}^{-1}$ ) of human genomic DNA (Promega, Madison, WI, USA) from multiple anonymous donors. Standard curves were created for both ALU115 and ALU247 primer sets by PCR amplifying 10-fold serially diluted human genomic DNA samples (Supplementary Figure 1A). A melting curve was drawn after each PCR to insure only one peak was amplified for all samples (Supplementary Figure 1B). Each plate consisted of a serum DNA sample and a negative control (water template) and a positive control (human genomic DNA) in each plate run. Each assay was carried out in duplicate. Laboratory personnel performing the qPCR assays was blinded to the clinical diagnoses of the patients.

Reference value of serum DNA. The concentration of ccf-DNA (ALU115 and ALU247) in each sample was calculated according to the standard curve. DNA integrity index was calculated as the ratio of qPCR result (ALU247/115). A receiver-operating characteristic (ROC) curve was created to select the Youden's index (Youden's index $=$ sensitivity + specificity -1 ) (Fluss et al, 2005; Nakas et al, 2010; Yin and Tian, 2014), and the highest sensitivity and specificity were selected as the cutoff values. A value greater than or equal to the cutoff value was considered positive, and smaller values were regarded as negative.

ARCHITECT assay. The concentrations of CEA in the serum samples from CRC patients were determined in the Clinical Pathology Laboratory of the Affiliated Hospital of Nantong University by ARCHITECT I2000 SR (Abbott, Chicago, IL, USA). A content of CEA $>5 \mathrm{ng} \mathrm{ml}^{-1}$ was considered abnormal.

Statistical analysis. The Mann-Whiney $U$-test was used to compare the ALU115 or ALU247/115 of serum DNA between CRC patients and controls. Kruskal-Wallis $H$-test was used for multiple comparisons between the groups. Receiver-operating characteristic curves and area under the ROC curve (AUC) were used to assess the diagnostic value of using ALU115, ALU247/ 115 and CEA for CRC. Statistical analyses were performed using SPSS Statistics 17.0 software (SPSS Inc., Chicago, IL, USA) and results were considered statistically significant at $P<0.05$ 
(two tailed). The corresponding experimental figures were drawn using GraphPad Prism v 5.0 software (Graphpad Software Inc, La Jolla, CA, USA).

\section{RESULTS}

The absolute concentration and integrity index of serum DNA in normal controls, intestinal polyp patients and primary CRC patients

Normal controls. The median (IQR 25-75) age of the 110 normal controls (56 males and 54 females) was 49 (40.75-59.00) years. The median absolute serum DNA concentration (ALU115) was 385.4 (205.7-597.1) $\mathrm{ng} \mathrm{ml}^{-1}$ and the median serum DNA integrity index (ALU247/115) was $0.38(0.29-0.49)$ in normal controls. The ALU115 and ALU247/115 of serum DNA in normal controls were independent of sex and age.

Intestinal polyps. The median age of the 63 intestinal polyp patients (44 males and 19 females) was 61 (52.00-68.00) years, in whom the median ALU115 was 423.3 (254.5-608.9) $\mathrm{ng} \mathrm{ml}^{-1}$ and the median ALU247/115 was $0.41(0.33-0.50)$. There was no statistical difference in ALU115 and ALU247/115 of serum DNA between the patients with intestinal polyps and normal controls $(P>0.05)$ (Figure 1).

Primary CRC patients. The median age of the 104 primary CRC patients (58 males and 46 females) was 66 (53.25-74.00) years. The median ALU115 and ALU247/115 in primary CRC patients were $1046.0 \quad(582.7-1694.0) \mathrm{ng} \mathrm{ml}^{-1}$ and 0.62 (0.51-0.65), respectively, which were significantly higher than those in normal controls and intestinal polyp patients (both $P<0.0001$ ). Youden index was maximal when ALU115 was $694.0 \mathrm{ng} \mathrm{ml}^{-1}$ and ALU247/115 was 0.52, and therefore these two values were defined as the cutoff value of ALU115 and ALU247/115, respectively (Figure 1).

Clinical characteristics of primary CRC patients. Serum samples were enrolled from a total of 104 primary CRC patients. An analysis on ALU115 and ALU247/115 in different subgroups of primary CRC patients with respect to gender, age, tumour size, tumour site, histologic differentiation, tumour stage (TNM) and intestinal polyps indicates that ALU115 and ALU247/115 in primary CRC patients were correlated with age, histologic differentiation and tumour stage $(P<0.05)$ (Table 1$)$.

Quantitative detection of CEA. The median serum CEA concentration was $3.4(<0.5-710.5) \mathrm{ng} \mathrm{ml}^{-1}$ in primary CRC patients $v s 1.6(0.3-4) \mathrm{ng} \mathrm{ml}^{-1}$ in the normal controls, showing a significant difference between them $(P<0.05)$.

Diagnostic utility of serum ALU115, ALU247/115 and CEA in primary CRC patients. Serum ALU115, ALU247/115 and CEA levels were determined in the 104 primary CRC patients and 110 normal controls (Table 2). Receiver-operating characteristic curves were drawn for distinguishing primary CRC patients from normal controls (Figure 2).

The AUC for distinguishing primary CRC patients from normal controls by ALU115 was 0.85 (95\% CI: 0.81-0.91). Youden index was maximal when the concentration of ccf-DNA was $694.0 \mathrm{ng} \mathrm{ml}^{-1}$, and therefore it was defined as the cutoff value. At this cutoff value, the sensitivity was $69.23 \%$ (95\% CI: $59.42-$ $77.90)$ at a specificity of $99.09 \%$ (95\% CI: 95.04-99.98), the accuracy was $84.58 \%$, the positive predictive value was $98.63 \%$ and the negative predictive value was $77.30 \%$. The AUC of serum ALU247/115 was 0.89 (95\% CI: 0.85-0.93). When 0.52 was defined as the cutoff value, the sensitivity was $73.08 \%$ (95\% CI: $63.49-$ 81.31 ) at a specificity of $97.27 \%$ (95\% CI: 92.24-99.43), and the accuracy, positive predictive value and negative predictive value were $85.51 \%, 96.20 \%$ and $79.26 \%$, respectively. The AUC of serum CEA was 0.78 (95\% CI: 72.9-84.9). When $5 \mathrm{ng} \mathrm{ml}^{-1}$ was defined as the cutoff value, the sensitivity was $42.31 \%$ (95\% CI: $31.77-$ 51.42 ) at a specificity of $100 \%$ (95\% CI: 96.70-100), and the accuracy, positive predictive value and negative predictive value were $71.96 \%, 100 \%$ and $64.71 \%$, respectively (Figure 2 and Table 3).

Detection of ALU115 and ALU247/115 in combination with CEA. Compared with the diagnostic efficiency of ALU115, ALU247/115 or CEA alone, combined detection improved the diagnostic efficiency of primary CRC to some extent (Table 3).

The absolute concentration and integrity index of serum DNA in operated, recurrent CRC/MCRC patients. The median (IQR 25-75) age of the 85 operated CRC patients (46 males and 39 females) was $62(51.00-69.00)$ years. The median ALU115 and ALU247/115 in these operated CRC patients were 524.1 (247.7-775.1) $\mathrm{ng} \mathrm{ml}^{-1}$ and $0.48(0.35-0.55)$, respectively, which were significantly lower than those in primary CRC and recurrent CRC/MCRC patients (both $P<0.0001$ ) (Figure 3).

The median age of the 16 recurrent CRC/MCRC patients (11 males and 5 females) was $68(52.50-72.75)$ years. The median ALU115 and ALU247/115 in these patients were 2228.1 (1293.0-3478.0) $\mathrm{ng} \mathrm{ml}^{-1}$ and $0.68(0.63-0.77)$, respectively, which were significantly higher than those in primary $(P=0.0021, P=0.0018)$ and operated CRC patients (both $P<0.0001$ ) (Figure 3 ).
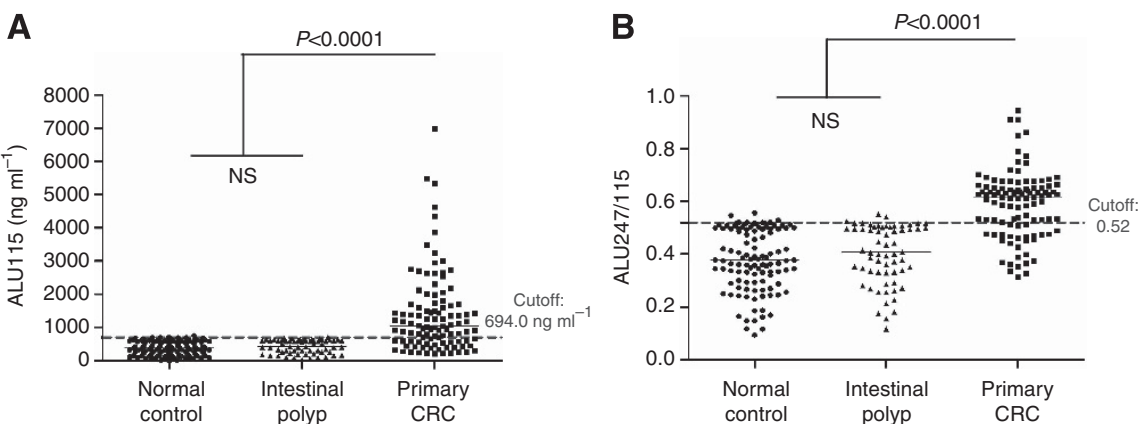

Figure 1. Scatter plots of ALU115 and ALU247/115 in serum from normal controls, intestinal polyp patients and primary CRC patients. (A) ALU115 and (B) ALU247/115 were determined by ALU-qPCR. The Mann-Whiney U-test was used to compare the ALU115 and ALU247/115 of serum DNA between the primary CRC patients and controls. P-values $<0.05$ were considered statistically significant. Horizontal lines indicate the median for each group. The dashed line indicates the cutoff value. Abbreviation: NS=no statistically significant difference. 
Table 1. ALU115 and ALU247/115 of serum DNA in subgroups of primary CRC patients $(n=104)$

\begin{tabular}{|c|c|c|c|c|c|}
\hline \multirow[b]{2}{*}{ Clinical characteristics } & \multirow[b]{2}{*}{ No. } & \multicolumn{2}{|c|}{ ALU115 (ng ml ${ }^{-1}$ ) } & \multicolumn{2}{|c|}{ ALU247/115 } \\
\hline & & Median (IQR 25-75) & $P$-value & Median (IQR 25-75) & $P$-value \\
\hline All & 104 & $1046.0(582.7-1694.0)$ & & $0.62(0.51-0.65)$ & \\
\hline Age (years) & & & 0.026 & & 0.043 \\
\hline $\begin{array}{l}\leqslant 60 \\
>60\end{array}$ & $\begin{array}{l}45 \\
59\end{array}$ & $\begin{array}{r}1262.0(749.0-2359.0) \\
857.5(479.4-1449.0)\end{array}$ & & $\begin{array}{l}0.63(0.53-0.68) \\
0.59(0.47-0.64)\end{array}$ & \\
\hline Gender & & & 0.255 & & 0.191 \\
\hline $\begin{array}{l}\text { Male } \\
\text { Female }\end{array}$ & $\begin{array}{l}58 \\
46\end{array}$ & $\begin{array}{l}1098.0(639.9-1993.0) \\
1028.0(500.3-1456.0)\end{array}$ & & $\begin{array}{l}0.62(0.53-0.67) \\
0.61(0.47-0.64)\end{array}$ & \\
\hline Tumour size $(\mathrm{cm})$ & & & 0.869 & & 0.683 \\
\hline $\begin{array}{l}\leqslant 5 \\
>5\end{array}$ & $\begin{array}{l}66 \\
38\end{array}$ & $\begin{array}{r}1125.0(604.6-1709.0) \\
937.8(541.7-2051.0)\end{array}$ & & $\begin{array}{l}0.62(0.51-0.66) \\
0.60(0.49-0.66)\end{array}$ & \\
\hline Tumour site & & & 0.87 & & 0.604 \\
\hline $\begin{array}{l}\text { Left } \\
\text { Right } \\
\text { Transverse } \\
\text { Rectal }\end{array}$ & $\begin{array}{r}19 \\
23 \\
6 \\
56\end{array}$ & $\begin{array}{c}1374.0(593.0-2182.0) \\
1079.0(611.0-2007.0) \\
1343.0(1052.0-2387.0) \\
930.1(536.7-1577.0)\end{array}$ & & $\begin{array}{l}0.64(0.46-0.68) \\
0.61(0.51-0.65) \\
0.63(0.58-0.68) \\
0.60(0.48-0.65)\end{array}$ & \\
\hline Histologic differentiation & & & 0.022 & & 0.038 \\
\hline $\begin{array}{l}\text { High } \\
\text { Middle } \\
\text { Low }\end{array}$ & $\begin{array}{l}21 \\
69 \\
14\end{array}$ & $\begin{array}{c}555.5(419.1-864.7) \\
1079.0(609.7-1470.0) \\
2679.0(1910.0-3310.0)\end{array}$ & & $\begin{array}{l}0.52(0.45-0.60) \\
0.62(0.51-0.64) \\
0.69(0.65-0.75)\end{array}$ & \\
\hline Tumour stage (TNM) & & & 0.005 & & 0.011 \\
\hline $\begin{array}{l}\text { I-II } \\
\text { III-IV } \\
\text { Not evaluable }\end{array}$ & $\begin{array}{l}54 \\
35 \\
15\end{array}$ & $\begin{array}{r}935.9(412.4-1456.0) \\
1374.0(785.0-2535.0) \\
828.7(510.4-2124.0)\end{array}$ & & $\begin{array}{l}0.60(0.46-0.64) \\
0.63(0.58-0.68) \\
0.59(0.47-0.67)\end{array}$ & \\
\hline Intestinal polyps & & & 0.577 & & 0.685 \\
\hline $\begin{array}{l}\text { With } \\
\text { Without }\end{array}$ & $\begin{array}{l}22 \\
82\end{array}$ & $\begin{array}{l}1296.0(410.9-2362.0) \\
1028.0(584.7-1690.0)\end{array}$ & & $\begin{array}{l}0.63(0.47-0.68) \\
0.61(0.51-0.65)\end{array}$ & \\
\hline
\end{tabular}

Table 2. ALU115, ALU247/115 and CEA in primary CRC patients and normal controls, median (IQR 25-75)

\begin{tabular}{|l|c|c|c|c|c|}
\hline Marker & Primary CRC & Normal controls & Cutoff & AUC & $P$-value \\
\hline ALU115 $\left(\mathrm{ng} \mathrm{ml}^{-1}\right)$ & $1046.0(582.7-1694.0)$ & $385.4(205.7-597.1)$ & 694 & 0.85 & $<0.0001$ \\
\hline ALU247/115 & $0.62(0.51-0.65)$ & $0.38(0.29-0.49)$ & 0.52 & 0.89 & $<0.0001$ \\
\hline CEA $\left(\mathrm{ng} \mathrm{ml}^{-1}\right)$ & $3.4(<0.5-710.5)$ & $1.6(0.3-4.0)$ & 5 & 0.78 & $<0.0001$ \\
\hline
\end{tabular}

Ccf-DNA dynamics in postoperative CRC patients. Pre- and postoperative ccf-DNA was measured in 20 of the 104 primary CRC who received surgery and were followed up. ALU115 and ALU247/115 of serum DNA determined before surgery (day 0) in these patients varied widely, ranging from 695.5 to 6987 (median 1142.0) $\mathrm{ng} \mathrm{ml}^{-1}$ and $0.49-0.95$ (median 0.62), respectively (Table 4).

At the first postoperative follow-up visit on 1-10 days, $75 \%$ of CRC patients displayed a slight increase in ALU115 and ALU247/ 115 , and the remaining $25 \%$ of CRC patients displayed a linear or sharp decrease in ALU115 and ALU247/115. In general, ALU115 ranged from 929.7 to 2652.0 (median 1268.0) $\mathrm{ng} \mathrm{ml}^{-1}$, and ALU247/115 ranged from 0.59 to 0.68 (median 0.63). At 20-50 days after surgical intervention, a sharp drop in ALU115 and ALU247/115 was observed in these 20 subjects. ALU115 ranged from 234.7 to 974.0 (median 668.3) $\mathrm{ng} \mathrm{ml}^{-1}$, and ALU247/115 ranged from 0.34 to 0.59 (median 0.48). At $60-120$ days after surgery, ALU115 ranged from 90.0 (median 282.2) $\mathrm{ng} \mathrm{ml}^{-1}$, and ALU247/115 ranged from 0.23 to 0.48 (median 0.35) (Figure 4).

There was a general trend that ALU115 and ALU247/115 were significantly higher before surgery, and decreased progressively in the follow-up period after surgery.

\section{DISCUSSION}

The detection of ccf-DNA has been recognised as a promising candidate biomarker for early detection and prognosis monitoring of CRC. The extraction methods for ccf-DNA mainly included the phenol-chloroform method (PCI-glycogen), the sodium iodide 
method (NaI method), various commercial DNA isolation kits and the magnetic bead method. Different DNA extraction methods from serum of CRC were compared (Supplementary Table 1). Analogously, comparison of serum/plasma DNA extraction

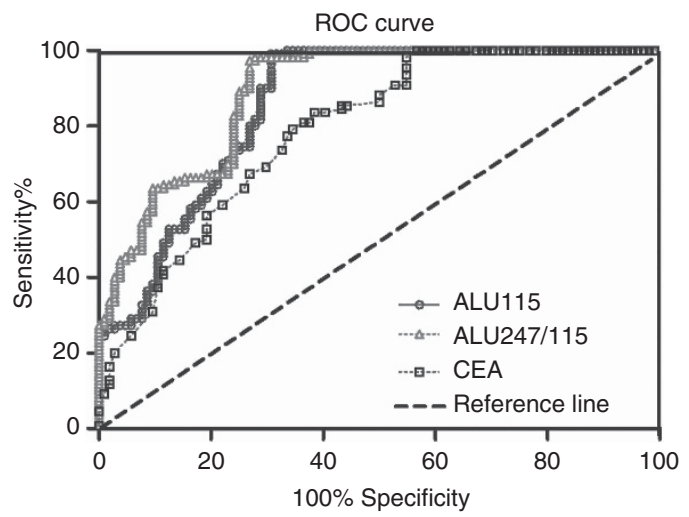

Figure 2. Receiver-operating characteristic curves for distinguishing primary CRC patients from normal controls. The AUC of ALU115, ALU247/115 and CEA was 0.85 (95\% Cl: 0.81-0.91), 0.89 (95\% Cl: $0.85-0.93)$ and $0.78(95 \% \mathrm{Cl}: 0.72-0.84)$, respectively. methods for detecting Mycobacterium tuberculosis (MTB) by real-time PCR was published by Pan et al (2013). Their study was to compare the four DNA extraction methods (phenol-chloroform method, Qiagen Kit (Qiagen, Hilden, Germany), Omega Kit (Omega, Norcross, GA, USA) and magnetic bead method) for detecting MTB, and use the best one in the diagnosis of MTB. The highest MTB DNA concentration was observed using the magnetic bead method, which is the best one for the DNA extraction of MTB (Supplementary Table 2).

In our study, ccf-DNA from $200 \mu$ l equivalent volume of serum was extracted using a novel nucleic acid-automated magnetic beadbased approach; furthermore, we measured the serum DNA concentration (ALU115) and DNA integrity index (ALU247/115) by real-time PCR amplification of 115- and 247-bp sequence within ALU repeats on the basis of previous frameworks (Wang et al, 2003; Umetani et al, 2006a, b). The result showed that the median serum ALU115 in 104 primary CRC patients was $1046.0 \mathrm{ng} \mathrm{ml}^{-1}$, in 85 operated CRC patients was $524.1 \mathrm{ng} \mathrm{ml}^{-1}$ and in 16 recurrent CRC/MCRC patients was $2228.1 \mathrm{ng} \mathrm{ml}^{-1}$. We also repeated this extracting method for 81 gastric cancer (GC) patients, 13 patients with gastric polyps and 17 pancreatic cancer (PC) patients, and detected serum ALU115 and ALU247/115 by ALU-qPCR. Results indicated that the median serum ALU115 was 1034 (449.5-2045.0) $\mathrm{ng} \mathrm{ml}^{-1}$ and the median ALU247/115 was $0.58(0.42-0.68)$ in GC patients, which were significantly higher than those in gastric polyps $\left(394.2 \mathrm{ng} \mathrm{ml}^{-1}, 0.39\right)$ and 110 normal

Table 3. Diagnostic value of ALU115, ALU247/115 and CEA for primary CRC patients

\begin{tabular}{|l|c|r|r|r|r|}
\hline Marker & \% Sensitivity & \% Specificity & \% Accuracy & $\begin{array}{c}\text { \% Positive predictive } \\
\text { value }\end{array}$ & $\begin{array}{c}\text { \% Negative } \\
\text { predictive value }\end{array}$ \\
\hline ALU115 & $69.23(72 / 104)$ & $99.09(109 / 110)$ & $84.58(181 / 214)$ & $98.63(72 / 73)$ & $77.3(109 / 141)$ \\
\hline ALU247/115 & $73.08(76 / 104)$ & $97.27(107 / 110)$ & $85.51(183 / 214)$ & $96.2(76 / 79)$ & $79.26(107 / 135)$ \\
\hline CEA & $42.31(44 / 104)$ & $100(110 / 110)$ & $71.96(154 / 214)$ & $100(44 / 44)$ & $64.71(110 / 170)$ \\
\hline ALU115+ CEA & $82.69(86 / 104)$ & $99.09(109 / 110)$ & $91.12(195 / 214)$ & $98.85(86 / 87)$ & $85.82(109 / 127)$ \\
\hline ALU247/115+CEA & $84.62(88 / 104)$ & $97.27(107 / 110)$ & $91.12(195 / 214)$ & $96.7(88 / 91)$ & $86.99(107 / 123)$ \\
\hline ALU115+ALU247/115+CEA & $85.57(89 / 104)$ & $97.27(107 / 110)$ & $91.59(196 / 214)$ & $96.74(89 / 92)$ & $87.7(107 / 122)$ \\
\hline Abbreviations: CEA carcinoembryonic antigen; CRC $=$ colorectal cancer. & & & \\
\hline
\end{tabular}

A

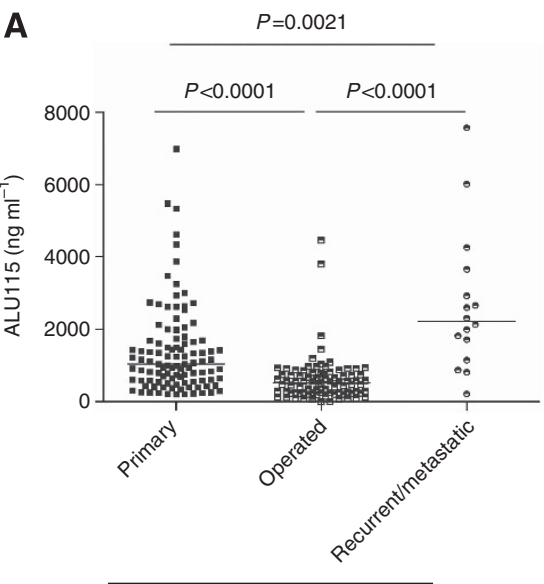

$\mathrm{CRC}$
B

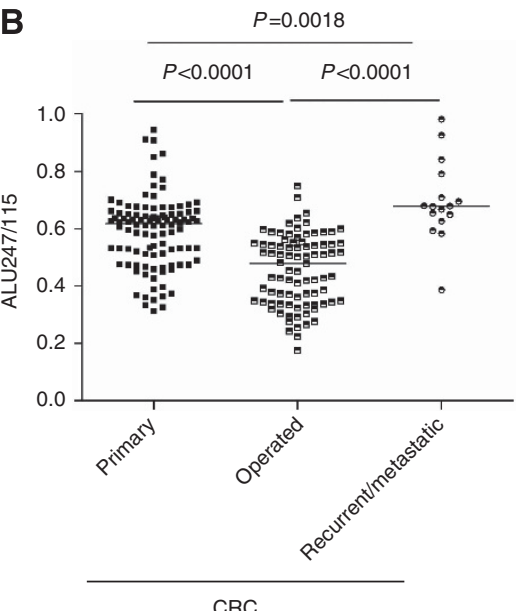

Figure 3. Scatter plots of serum ALU115 and ALU247/115 from primary, operated and recurrent CRC/MCRC patients. (A) ALU115 and (B) ALU247/115 were determined by ALU-qPCR. The Mann-Whiney U-test was used to assess the ALU115 and ALU247/115 of serum DNA between primary, operated and recurrent CRC/MCRC patients. P-values $<0.05$ were considered statistically significant. Horizontal lines indicate the median for each group. 


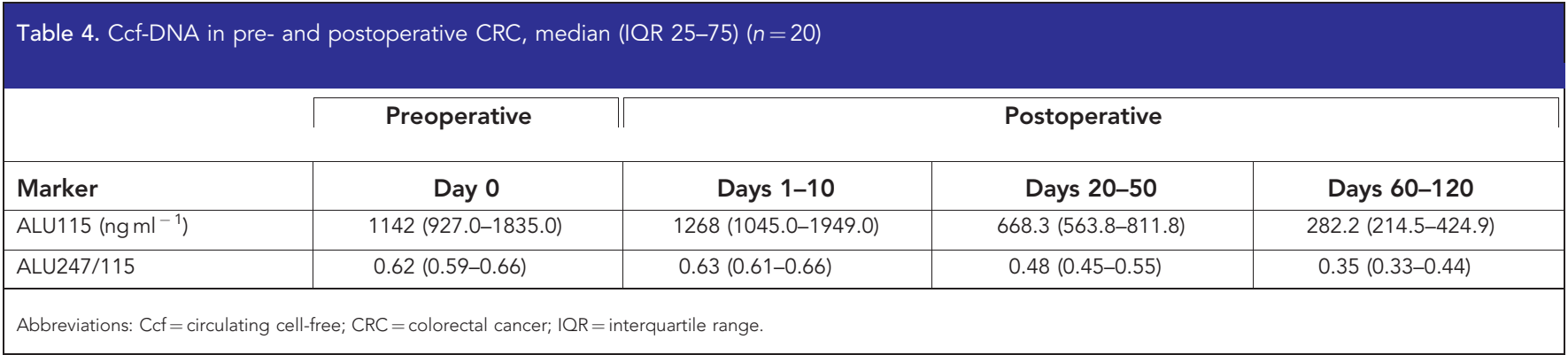
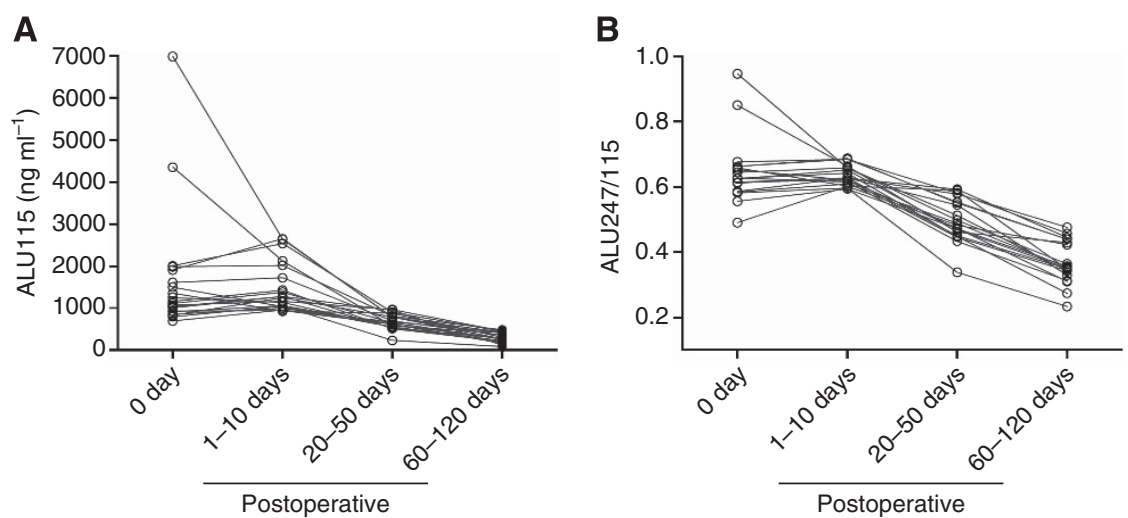

Figure 4. Line charts of pre- and postoperative serum ALU115 and ALU247/115 in CRC patients. (A) ALU115 and (B) ALU247/115 were determined by ALU-qPCR, and ccf-DNA was monitored in the 20 surgical CRC patients.

controls $\left(385.4 \mathrm{ng} \mathrm{ml}^{-1}, 0.38\right.$ ) (both $P<0.01$ ). The median serum ALU115 and ALU247/115 in PC patients were 1239 (820.21924.0) $\mathrm{ng} \mathrm{ml}^{-1}$ and $0.60(0.52-0.70)$, respectively, which were remarkably higher than those in 110 normal controls $\left(385.4 \mathrm{ng} \mathrm{ml}^{-1}, 0.38\right)(P<0.01)$. The new magnetic bead method has proved to be fast and high throughput, and can produce high yields of DNA with minimum human errors, thus guaranteeing high reproducibility.

The ALU sequences were chosen, knowing that they are the most abundant and active repeated elements in the human genome, typically 300 nucleotides in length, accounting for more than $10 \%$ of the genome (Dagan et al, 2004; Cardelli, 2011). Species specificity and highly repeatability of ALU sequences can be used for sensitive quantification of human genomic DNA in neoplastic specimen extracts (Umetani et al, 2006a, b; Zou et al, 2006; Mead et al, 2011; Sriram et al, 2012; Feng et al, 2013; Qi et al, 2013) or quantify human tumour xenograft burden in murine and integrated HIV-1 DNA in infected HeLa cells (Brussel and Sonigo, 2003).

It was found that ccf-DNA in patients with primary CRC was significantly higher than that in patients with intestinal polyps and healthy controls (both $P<0.0001$ ). In addition, ccf-DNA was found to be significant correlated with age, histologic differentiation and tumour stage (TNM) in patients with primary CRC $(P<0.05)$. Compared with colorectal polyps, primary CRC patients with low levels of the ccf-DNA were found in 33 out of 104 specimens, and 9 had stage I $\left(\mathrm{T}_{1-2} \mathrm{~N}_{0} \mathrm{M}_{0}\right)$ disease, 12 had stage II $\left(\mathrm{T}_{3-4} \mathrm{~N}_{0} \mathrm{M}_{0}\right), 6$ had stage III $\left(\mathrm{T}_{\text {any }} \mathrm{N}_{1-2} \mathrm{M}_{0}\right)$ and 6 had not been evaluated. Additional patients would need to be recruited to our study to explore further the role of the aggressive cancers at different stages of CRC.

In this translational study, we evaluated the diagnostic utility of ccf-DNA absolute concentration, DNA integrity index and CEA by ALU-qPCR in 277 serum samples from patients with primary CRC or intestinal polyps and normal controls. Receiver-operating characteristic curve AUC of ALU115, ALU247/115 index and
CEA levels for distinguishing primary CRC patients from normal controls was $0.85,0.89$ and 0.78 , respectively, indicating that the AUC of DNA integrity index is higher than ALU115 and CEA. Compared with the diagnostic efficiency of ALU115, ALU247/115 or CEA alone, combined detection improved the diagnostic efficiency of primary CRC to some extent. Flamini et al (2006) compared the sensitivity and specificity of ccf-DNA with the conventional serum marker CEA and found that ccf-DNA, when used in combination with CEA, was a potentially useful tool for the diagnosis of early-stage CRC. Our results showed that combined detection of ALU115, ALU247/115 and CEA improved the diagnostic efficiency of primary CRC. To the best of our knowledge, this is the first study that reported combined detection of DNA integrity index and CEA to improve the diagnostic efficiency of CRC through quantification of ALU repeats.

Many studies (Frattini et al, 2006; Diehl et al, 2008) have demonstrated that ccf-DNA level is remarkably high in CRC patients during recurrence/metastasis. It was found in our study that ccf-DNA was detectable in 101 serum samples from operated and recurrent CRC/MCRC patients, and that ALU115 and ALU247/115 were significantly higher in recurrent CRC/MCRC patients than those in operated CRC patients, suggesting that ccfDNA may prove to be a promising candidate biomarker for prognostic prediction of CRC.

Finally, we assessed ccf-DNA dynamics in surgical CRC patients. Follow-up data obtained from 20 of these patients showed that there was a general trend of decrease in ALU115 and ALU247/115 after surgery as compared with those before surgery, although the rate of decrease after surgery was different in all cases. For instance, a linear or sharp decrease was observed in some cases, whereas there was a slight increase in some other cases at the first follow-up visit 1-10 days. This slight increase may be because of the residual tumour tissue during the surgical procedure or postoperative inflammation, with subsequent release of ccf-DNA. A marked decrease was observed almost in all cases 20-120 days 
after surgery. Therefore, detection of changes in the serum concentration of ccf-DNA and integrity index may prove useful for dynamic monitoring of the prognosis of CRC patients who underwent surgical intervention.

In conclusion, the automated magnetic bead-based technique is accurate and reproducible for extraction of ccf-DNA in serum samples, and a routine test for ccf-DNA fragments by real-time PCR with ALU repeats is feasible. ALU115 and ALU247/115 index in serum are significantly higher in patients with primary CRC than those in patients with intestinal polyps and healthy controls. Combined detection of ALU115, ALU247/115 and CEA could improve the diagnostic efficiency for CRC. Serum DNA concentrations and integrity index may be valuable in early complementary diagnosis and monitoring of progression and prognosis of CRC. Further larger-scale and longer prospective studies are needed to confirm the clinical utility of serum DNA in the diagnosis and prognostic prediction of CRC.

\section{ACKNOWLEDGEMENTS}

This study was supported by a grant from the National Nature Science Foundation (81301498; 81271920) and the Medical Innovation Team and Leading Talent Project (LJ201133) of the Jiangsu Province.

\section{CONFLICT OF INTEREST}

The authors declare no conflict of interest.

\section{REFERENCES}

Banki F, Mason RJ, Oh D, Hagen JA, DeMeester SR, Lipham JC, Tanaka K, Danenberg KD, Yacoub WN, Danenberg PV, DeMeester TR (2007) Plasma DNA as a molecular marker for completeness of resection and recurrent disease in patients with esophageal cancer. Arch Surg 142: 533-538.

Brussel A, Sonigo P (2003) Analysis of early human immunodeficiency virus type 1 DNA synthesis by use of a new sensitive assay for quantifying integrated provirus. J Virol 77: 10119-10124.

Cardelli M (2011) Alu PCR. Methods Mol Biol 687: 221-229.

Chan KC, Leung SF, Yeung SW, Chan AT, Lo YM (2008) Persistent aberrations in circulating DNA integrity after radiotherapy are associated with poor prognosis in nasopharyngeal carcinoma patients. Clin Cancer Res 14: 4141-4145.

Chen H, Sun LY, Zheng HQ, Zhang QF, Jin XM (2012) Total serum DNA and DNA integrity: diagnostic value in patients with hepatitis $B$ virus-related hepatocellular carcinoma. Pathology 44: 318-324.

Chen K, Zhang H, Zhang LN, Ju SQ, Qi J, Huang DF, Li F, Wei Q, Zhang J (2013) Value of circulating cell-free DNA in diagnosis of hepatocelluar carcinoma. World J Gastroenterol 19: 3143-3149.

Czeiger D, Shaked G, Eini H, Vered I, Belochitski O, Avriel A, Ariad S, Douvdevani A (2011) Measurement of circulating cell-free DNA levels by a new simple fluorescent test in patients with primary colorectal cancer. Am J Clin Pathol 135: 264-270.

da Silva Filho BF, Gurgel AP, Neto MA, de Azevedo DA, de Freitas AC, Silva Neto Jda C, Silva LA (2013) Circulating cell-free DNA in serum as a biomarker of colorectal cancer. J Clin Pathol 66: 775-778.

Dagan T, Sorek R, Sharon E, Ast G, Graur D (2004) AluGene: a database of Alu elements incorporated within protein-coding genes. Nucleic Acids Res 32: D489-D492.

Diehl F, Schmidt K, Durkee KH, Moore KJ, Goodman SN, Shuber AP, Kinzler KW, Vogelstein B (2008) Analysis of mutations in DNA isolated from plasma and stool of colorectal cancer patients. Gastroenterology 135: 489-498.

Ellinger J, Wittkamp V, Albers P, Perabo FG, Mueller SC, von Ruecker A, Bastian PJ (2009) Cell-free circulating DNA: diagnostic value in patients with testicular germ cell cancer. J Urol 181: 363-371.
Feng J, Gang F, Li X, Jin T, Houbao H, Yu C, Guorong L (2013) Plasma cell-free DNA and its DNA integrity as biomarker to distinguish prostate cancer from benign prostatic hyperplasia in patients with increased serum prostate-specific antigen. Int Urol Nephrol 45: 1023-1028.

Ferlay J, Shin HR, Bray F, Forman D, Mathers C, Parkin DM (2010) Estimates of worldwide burden of cancer in 2008: GLOBOCAN 2008. Int J Cancer 127: 2893-2917.

Flamini E, Mercatali L, Nanni O, Calistri D, Nunziatini R, Zoli W, Rosetti P, Gardini N, Lattuneddu A, Verdecchia GM, Amadori D (2006) Free DNA and carcinoembryonic antigen serum levels: an important combination for diagnosis of colorectal cancer. Clin Cancer Res 12: 6985-6988.

Fluss R, Faraggi D, Reiser B (2005) Estimation of the Youden Index and its associated cutoff point. Biom J 47: 458-472.

Frattini M, Gallino G, Signoroni S, Balestra D, Battaglia L, Sozzi G, Leo E, Pilotti S, Pierotti MA (2006) Quantitative analysis of plasma DNA in colorectal cancer patients: a novel prognostic tool. Ann NY Acad Sci 1075: $185-190$.

Fujimoto A, O'Day SJ, Taback B, Elashoff D, Hoon DS (2004) Allelic imbalance on 12q22-23 in serum circulating DNA of melanoma patients predicts disease outcome. Cancer Res 64: 4085-4088.

Gang F, Guorong L, An Z, Anne GP, Christian G, Jacques T (2010) Prediction of clear cell renal cell carcinoma by integrity of cell-free DNA in serum. Urology 75: 262-265.

Gao YJ, He YJ, Yang ZL, Shao HY, Zuo Y, Bai Y, Chen H, Chen XC, Qin FX, Tan S, Wang J, Wang L, Zhang L (2010) Increased integrity of circulating cell-free DNA in plasma of patients with acute leukemia. Clin Chem Lab Med 48: 1651-1656.

Giacona MB, Ruben GC, Iczkowski KA, Roos TB, Porter DM, Sorenson GD (1998) Cell-free DNA in human blood plasma: length measurements in patients with pancreatic cancer and healthy controls. Pancreas 17: 89-97.

Hanley R, Rieger-Christ KM, Canes D, Emara NR, Shuber AP, Boynton KA, Libertino JA, Summerhayes IC (2006) DNA integrity assay: a plasmabased screening tool for the detection of prostate cancer. Clin Cancer Res 12: 4569-4574.

Hauser S, Zahalka T, Ellinger J, Fechner G, Heukamp LC, VON Ruecker A, Müller SC, Bastian PJ (2010) Cell-free circulating DNA: diagnostic value in patients with renal cell cancer. Anticancer Res 30: 2785-2789.

Hohaus S, Giachelia M, Massini G, Mansueto G, Vannata B, Bozzoli V, Criscuolo M, D’Alò F, Martini M, Larocca LM, Voso MT, Leone G (2009) Cell-free circulating DNA in Hodgkin's and non-Hodgkin's lymphomas. Ann Oncol 20: 1408-1413.

Holdenrieder S, Burges A, Reich O, Spelsberg FW, Stieber P (2008) DNA integrity in plasma and serum of patients with malignant and benign diseases. Ann NY Acad Sci 1137: 162-170.

Jahr S, Hentze H, Englisch S, Hardt D, Fackelmayer FO, Hesch RD, Knippers R (2001) DNA fragments in the blood plasma of cancer patients: quantitations and evidence for their origin from apoptotic and necrotic cells. Cancer Res 61: 1659-1665.

Jemal A, Bray F, Center MM, Ferlay J, Ward E, Forman D (2011) Global cancer statistics. CA Cancer J Clin 61: 69-90.

Jiang WW, Zahurak M, Goldenberg D, Milman Y, Park HL, Westra WH, Koch W, Sidransky D, Califano J (2006) Increased plasma DNA integrity index in head and neck cancer patients. Int J Cancer 119: 2673-2676.

Keesee SK, Briggman JV, Thill G, Wu YJ (1996) Utilization of nuclear matrix proteins for cancer diagnosis. Crit Rev Eukaryot Gene Expr 6: 189-214.

Leon SA, Shapiro B, Sklaroff DM, Yaros MJ (1977) Free DNA in the serum of cancer patients and the effect of therapy. Cancer Res 37: 646-650.

Ludwig JA, Weinstein JN (2005) Biomarkers in cancer staging, prognosis and treatment selection. Nat Rev Cancer 5: 845-856.

Mead R, Duku M, Bhandari P, Cree IA (2011) Circulating tumour markers can define patients with normal colons, benign polyps, and cancers. Br J Cancer 105: 239-245.

Mutch MG (2007) Molecular profiling and risk stratification of adenocarcinoma of the colon. J Surg Oncol 96: 693-703.

Nakas CT, Alonzo TA, Yiannoutsos CT (2010) Accuracy and cut-off point selection in three-class classification problems using a generalization of the Youden index. Stat Med 29: 2946-2955.

Paci M, Maramotti S, Bellesia E, Formisano D, Albertazzi L, Ricchetti T, Ferrari G, Annessi V, Lasagni D, Carbonelli C, De Franco S, Brini M, 
Sgarbi G, Lodi R (2009) Circulating plasma DNA as diagnostic biomarker in non-small cell lung cancer. Lung Cancer 64: 92-97.

Pan S1, Gu B, Wang H, Yan Z, Wang P, Pei H, Xie W, Chen D, Liu G (2013) Comparison of four DNA extraction methods for detecting Mycobacterium tuberculosis by real-time PCR and its clinical application in pulmonary tuberculosis. J Thorac Dis 5(3): 251-257.

Pinzani P, Salvianti F, Zaccara S, Massi D, De Giorgi V, Pazzagli M, Orlando C (2011) Circulating cell-free DNA in plasma of melanoma patients: qualitative and quantitative considerations. Clin Chim Acta 412: 2141-2145.

Qi J, Qian C, Shi W, Wu X, Jing R, Zhang L, Wang Z, Ju S (2013) Alu-based cell-free DNA: a potential complementary biomarker for diagnosis of colorectal cancer. Clin Biochem 46: 64-69.

Sozzi G, Conte D, Leon M, Ciricione R, Roz L, Ratcliffe C, Roz E, Cirenei N, Bellomi M, Pelosi G, Pierotti MA, Pastorino U (2003) Quantification of free circulating DNA as a diagnostic marker in lung cancer. J Clin Oncol 21: 3902-3908.

Sriram KB, Relan V, Clarke BE, Duhig EE, Windsor MN, Matar KS, Naidoo R, Passmore L, McCaul E, Courtney D, Yang IA, Bowman RV, Fong KM (2012) Pleural fluid cell-free DNA integrity index to identify cytologically negative malignant pleural effusions including mesotheliomas. $B M C$ Cancer 12: 428.

Taback B, Hoon DS (2004a) Circulating nucleic acids and proteomics of plasma/serum: clinical utility. Ann NY Acad Sci 1022: 1-8.

Taback B, Hoon DS (2004b) Circulating nucleic acids in plasma and serum: past, present and future. Curr Opin Mol Ther 6: 273-278.
Umetani N, Giuliano AE, Hiramatsu SH, Amersi F, Nakagawa T, Martino S, Hoon DS (2006a) Prediction of breast tumour progression by integrity of free circulating DNA in serum. J Clin Oncol 24: 4270-4276.

Umetani N, Kim J, Hiramatsu S, Reber HA, Hines OJ, Bilchik AJ, Hoon DS (2006b) Increased integrity of free circulating DNA in sera of patients with colorectal or periampullary cancer: direct quantitative PCR for ALU repeats. Clin Chem 52: 1062-1069.

Wang BG, Huang HY, Chen YC, Bristow RE, Kassauei K, Cheng CC, Roden R, Sokoll LJ, Chan DW, Shih IeM (2003) Increased plasma DNA integrity in cancer patients. Cancer Res 63: 3966-3968.

Yin J, Tian L (2014) Joint confidence region estimation for area under ROC curve and Youden index. Stat Med 33: 985-1000.

Zachariah RR, Schmid S, Buerki N, Radpour R, Holzgreve W, Zhong X (2008) Levels of circulating cell-free nuclear and mitochondrial DNA in benign and malignant ovarian tumours. Obstet Gynecol 112: 843-850.

Zhong XY, Ladewig A, Schmid S, Wight E, Hahn S, Holzgreve W (2007) Elevated level of cell-free plasma DNA is associated with breast cancer. Arch Gynecol Obstet 276: 327-331.

Zou H, Harrington JJ, Klatt KK, Ahlquist DA (2006) A sensitive method to quantify human long DNA in stool: relevance to colorectal cancer screening. Cancer Epidemiol Biomarkers Prev 15: 1115-1119.

This work is published under the standard license to publish agreement. After 12 months the work will become freely available and the license terms will switch to a Creative Commons AttributionNonCommercial-Share Alike 3.0 Unported License.

Supplementary Information accompanies this paper on British Journal of Cancer website (http://www.nature.com/bjc) 